\title{
Laboratory investigation of backward erosion piping - effects of inclined exit face and constricted seepage exits
}

\author{
J.D. Rice \& I.A. Ibrahim \\ Utah State University, Logan, Utah, USA \\ R.A. Keizer Jr. \& R.A. Jaeger \\ GEI Consultants, Rancho Cordova, California, USA
}

\begin{abstract}
While the Backward Erosion Piping (BEP) form of internal erosion is one of the least understood mechanisms in geotechnical engineering, a precise, mechanism-based analysis method for backward erosion piping (BEP) remains elusive for geotechnical engineers. BEP is still generally analyzed with empirically-based methods that do not consider many of the complexities of the soil, the subsurface geometry, the seepage regime, and the exit face conditions. Furthermore, many of the analysis methods commonly used for BEP were actually developed for other forms of internal erosion and adapted to BEP by correlating with crude empirical data. This paper presents a laboratory testing program performed to investigate the mechanisms of BEP under two conditions often encountered in the field: 1) exiting on a sloping exit face, and 2) exiting into a constricted exit. The study builds upon previous research on the mechanisms of piping initiation performed at Utah State University using a similar apparatus. A variety of soils representing a range of grain size, grain shape, and gradations are subjected to increasing hydraulic gradients under a variety of exit face condition including sloped exit faces and a range of constricted seepage exits. The results are compared with three-dimensional finite element analyses in order to develop a better understanding of the BEP initiation process.
\end{abstract}

\section{BACKGROUND}

\subsection{Current and Historic Practice}

In current engineering practice, critical gradients for heave have been calculated using three theoretical methods. First, Terzaghi's derivation (Terzaghi 1922, Terzaghi and Peck 1948) of the heave mechanism compares the vertical hydraulic gradient at the seepage exit to the critical gradient, $i_{c r}$, needed to initiate erosion. Terzaghi defined the critical gradient through the following equation,

$i_{c r}=\frac{\gamma_{b}}{\gamma_{w}}$

where $\gamma_{\mathrm{b}}$ is the buoyant unit weight, and $\gamma_{\mathrm{w}}$ is the unit weight of water. Although Terzaghi derived this equation to model the heave mechanism, it is often used to predict other mechanisms such as backward erosion, or internal erosion in general. The correct application of the equation models heave with vertical seepage and a horizontal exit face. However, slope stability calculations, and case histories show that gradients much lower than predicted by Equation 1 can cause the imitation of erosion on inclined surfaces, eventually leading to internal erosion.
The United States Army Corps of Engineers (USACE) developed a simplified method to predict a factor of safety against heave using an effective seepage length based on the blanket thickness upstream and downstream (USACE, 1993). These equations have commonly been referred to as the Blanket Theory Equations.

O'Leary (O'Leary et al, 2013) correctly pointed out errors in a previously developed equation for estimating critical gradient when considering an inclined exit face, and proposed Equation 2, a modification to an equation developed by Kovács (1981):

$i_{c r}=\left(\frac{\gamma_{b}}{\gamma_{w}}\right)\left(\frac{\tan \left(\varphi^{\prime}\right) \cos (\beta)-\sin (\beta)}{\cos (\beta-\alpha)+\tan \left(\varphi^{\prime}\right) \sin (\beta-\alpha)}\right)$

where $\gamma_{b}$ is the buoyant unit weight, $\gamma_{\mathrm{w}}$ is the unit weight of water, $\varphi^{\prime}$ is the drained internal friction angle, $\beta$ is the slope angle from the horizontal, and $\alpha$ is the seepage angle (horizontal seepage is 0 , downward seepage is positive, and upward seepage is negative).

O'Leary indicated this equation calculates a critical gradient for backward erosion, however, the original derivation modeled a non-horizontal exit face, and non-vertical seepage. The model represents 
a macro-mechanism of internal erosion rather than a micro-mechanism like backward erosion particle detachment. Individual particle detachment depends on the size, angularity, gradation, relative density, and cohesion of the soil which is not considered in Equation 2.

Though these methods are useful for calculating possible critical gradients for the heave mechanism, they are all theoretical, and do not exhibit similar trends observed in laboratory testing presented herein.

\section{LABORATORY TESTING METHODS}

A testing apparatus and procedure was developed by Fleshman (2012) (Fleshman and Rice 2014a, 2014b) to observe critical gradients with vertical flow through sandy soils using a 5.1-centimeter diameter sampler. A schematic illustration of the device is presented in Figure 1. Essentially, the device imposes a hydraulic gradient through a soil sample while monitoring the pressures within the soil.

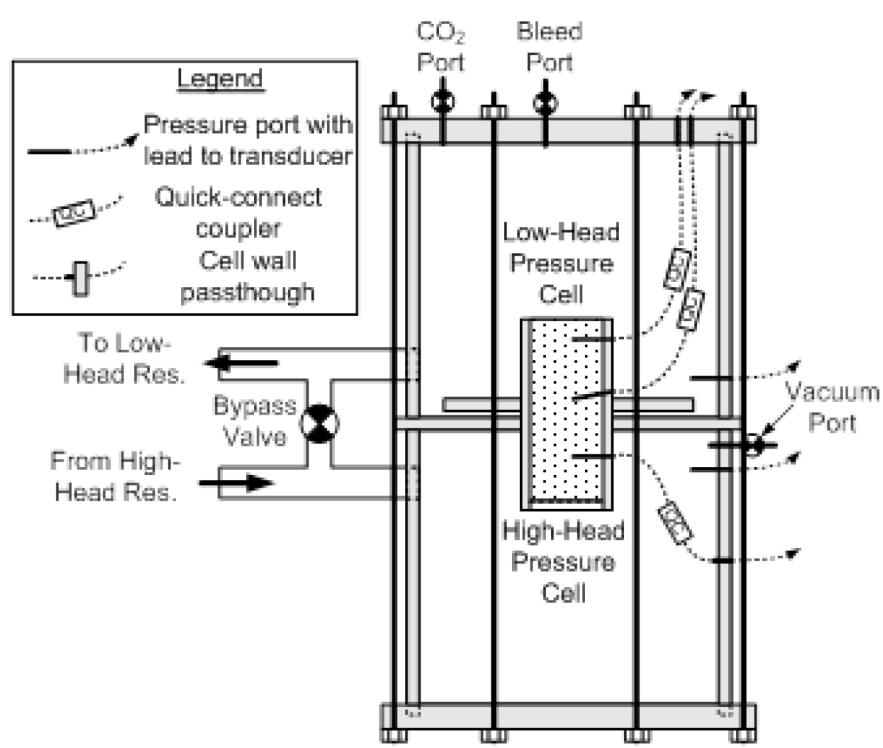

Figure 1. Schematic illustration of the testing device used in this study.

Tests were performed by gradually increasing the total differential head across the sample and measuring partial differential heads in the sensors embedded in the sample. The raw data from this procedure is presented in Figure 2A. To assist in interpreting the data the differential pore pressures at the sensors were divided by the theoretical value that would occur at the value of differential head without erosion occurring (ie. Constant head loss and gradient throughout the sample). The normalized data is presented in Figure 2B. Also plotted on Figure 2 are vertical lines representing the observed stages of erosion initiation. In general, four stages of erosion initiation were observed: 1) initial movement, the first detected movement of the uppermost sand grains, 2) heave progression, the downward progres- sion of soil loosening in the sample, 3) sand boil formation, and 4) total failure, where the sample completely heaved out of the holder. The downward progression of the soil loosening can be followed by the continued deviation of the normalized pore pressure sensor lines in Figure 2B. Details of this device are presented in Fleshman and Rice (2014a and 2014b).
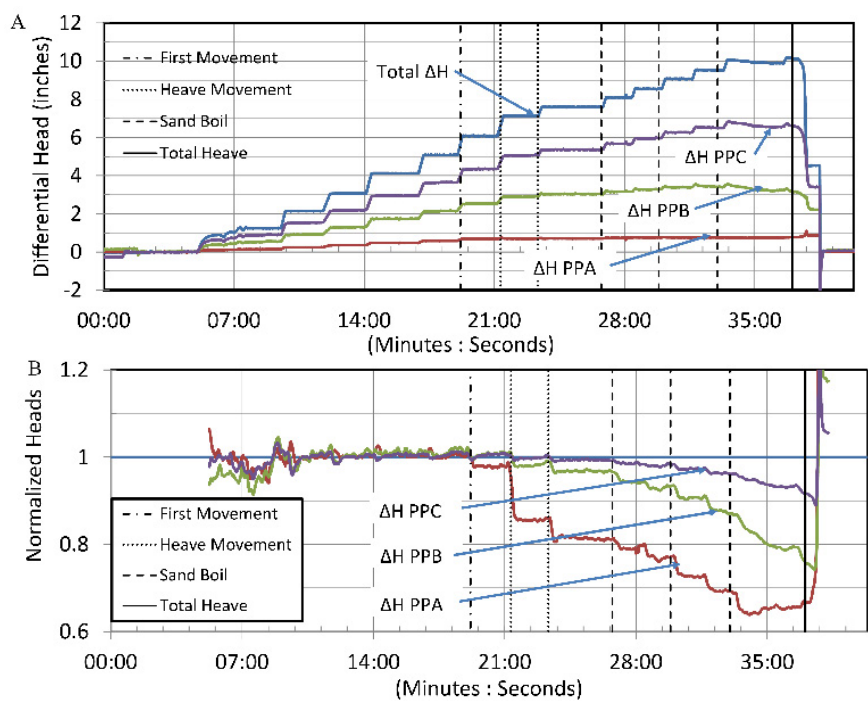

Figure 2. Data plots from tests with horizontal exit face: A) Raw data of total differential head and differential head at Sensors PPA, PPB and PPC; B) Normalized data from Sensors PPA, PPB and PPC.

\subsection{Sloped Exit-Face Testing}

Using similar methods, Keizer (2014) tested sandy soils at inclined exit face conditions using both the 5.1-centimeter diameter sampler, and a larger 10.2centimeter diameter sampler. Detailed procedures and results of the tests are presented in previous papers (Fleshman and Rice 2013, Swainston-Fleshman and Rice 2014a, 2014b, Keizer and Rice, 2015). The primary objectives of the study were to better understand the backward erosion "piping" mechanism through sandy soils, and to identify and evaluate stages which initiated failure.

In the work by Keizer (2014) and Keizer and Rice (2015), four stages of erosion initiation were observed in soil samples with horizontal and inclined exit face conditions: 1) first visible movement $\left(i_{m}\right)$, 2) boil formation $\left(i_{b}\right), 3$ ) heave $\left(i_{h}\right)$, and 4) total failure $\left(i_{f}\right)$. Stage 1 was observed under vertical flow and horizontal exit face conditions at critical gradients very similar to what Equation 1 (Terzaghi's Equation) would predict. This behavior is confirmed in the previous research (Fleshman 2012, Fleshman and Rice 2013, Swainston-Fleshman and Rice $2014 a, 2014 b)$. As the exit face inclination was increased, the gradient required to initiate stage 1 decreased. 


\subsection{Constricted Exit Testing}

Tests were also performed using a constricted seepage exit as shown in Figure 3. Each constricted exit apparatus consisted of a $10.2-\mathrm{cm}$ diameter sampler with a plate placed over the exit end. The plate contained a circular orifice leading to a $5.1-\mathrm{cm}$ riser tube with the same inside diameter as the orifice. Tests were performed using orifice diameters of 2.5, $1.9,0.63$, and 0.32 centimeters. Similar to the previous testing, the differential head across the sampler was increased and the stages of erosion initiation were observed.

Four stages of erosion initiation were observed throughout the testing: 1) first boiling, where soil particles are detached from the soil mass at one point along the perimeter of the orifice, 2) boiling around the entire perimeter, where the dislodging of particles is occurring around the perimeter but not the center of the orifice, 3) boiling of the whole mass, where all of the soil at the sample surface is dislodged in the orifice, and 4) boiling reach the top of riser, where the dislodged particles have now reached the top of the riser and are being removed from the sample. Photos of these stages are presented in Figure 3. In the tests using the two smaller orifices only the first and last stages were observed, that is, boiling initiated in the entire orifice at once and soil particles reached the top of the riser as soon as they were dislodged from the soil mass.

Data was collected from piezometers buried within the sample in the horizontal exit face tests. However, in these tests an additional sensor (PPD) was added below the edge of the orifice at a depth half way between PPA and the top of the sample. An example of the normalized data for these tests, which were plotted similarly to the horizontal exit face tests, is presented in Figure 4.
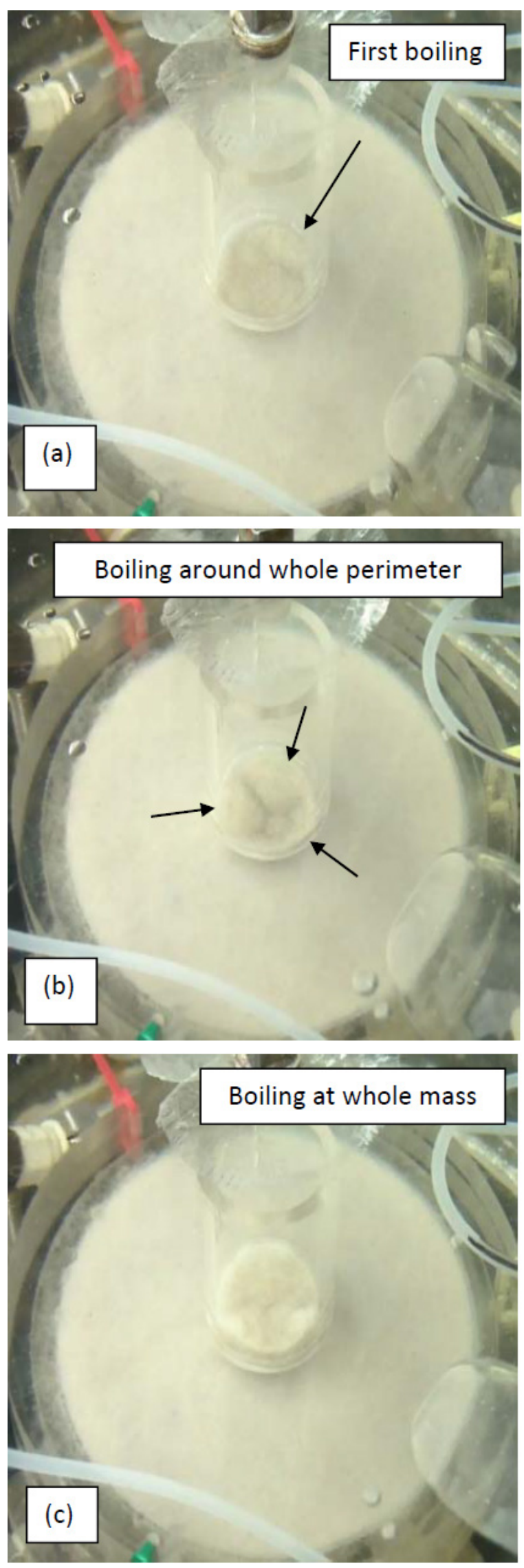

Figure 3. Photos of the first three stages of erosion initiation in constricted outlet tests. 


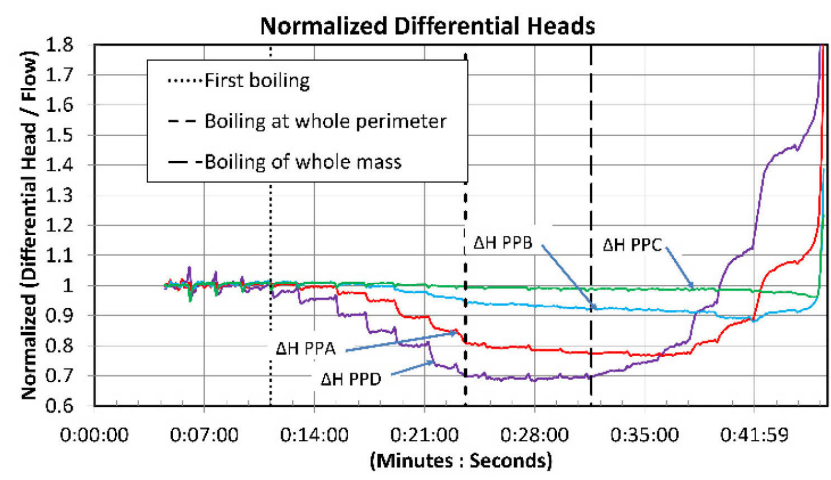

Figure 4. Normalized data plot for soil with constricted exit face (2.5-cm riser).

Note the data in Figure 4 is similar to that in Figure $2 \mathrm{~B}$ in the early portions of the test but displays very different behavior later in the test. Reasons for this observed behavior are discussed in Section 4.

\section{INTERPRETING RESULTS OF INCLINED TESTING}

A variety of soils were tested with inclined exit faces. To simplify comparison the inclinations of the exit faces were stated as increments of the percentage of the loose angle of repose (PAOR) for the corresponding soil type. Also, for comparison purposes, the resulting gradients are normalized to Terzaghi's critical gradient using Equation (3),

$i_{\text {crNorm }}=\frac{i}{\left(\frac{\gamma_{b}}{\gamma_{w}}\right)}$

where $i$ is the observed gradient at stage 1 .

The soils were all tested at 0 PAOR (Horizontal exit face), 25 PAOR ( $25 \%$ of loose angle of repose), 50 PAOR, 75 PAOR, 97 PAOR, and Failure angle (an angle determined in the lab by slowly inclining a dense soil sample until failure occurred without seepage). The Failure angle varied between 108 and 132 PAOR and was influenced by angularity, grain size, gradation, and specific gravity of the soil tested.

Figure 5 presents the critical gradients at stage 1 normalized to Terzaghi's critical gradients versus the PAOR test run using the 5.1-centimeter and 10.2-centimeter diameter samplers. Second-order polynomial trend lines for both sets of data are presented. A slightly higher trend for the smaller (5.1$\mathrm{cm}$ ) diameter sampler could be attributed to increased edge effects. The trends for the smaller and larger samplers give $\mathrm{R}^{2}$ values of 0.90 and 0.88 , respectively. The difference between the two sampler trends is small, both starting very close to what Terzaghi's prediction would indicate for a horizontal exit face, and both ending at a 0 critical gradient near 118-119 PAOR.

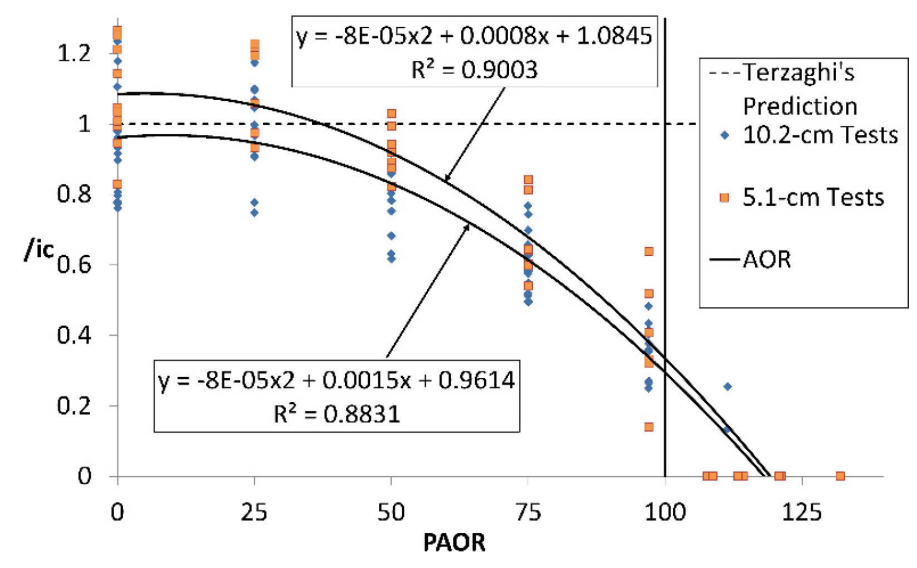

Figure 5. Plots of normalized critical gradients versus PAOR for $10.2-\mathrm{cm}$ and $5.1-\mathrm{cm}$ samplers.

\subsection{Proposed Model}

The proposed model assumes the soil critical gradient will exhibit a downward second order polynomial trend when plotting the PAOR versus gradient. The critical gradient is calculated using the following equation,

$i_{c r}=a * P A O R^{2}+b * P A O R+c($ for PAOR $\geq 8.8)$

where,

$a=-1.8 \times 10^{-6}(\gamma)+1.16 \times 10^{-4}$

and,

$b=1.9748 \times 10^{-5}(\gamma)-0.0016$

and,

$c=\frac{\gamma_{b}}{\gamma_{w}}$

where $\gamma$ is the unit weight of the soil (saturated), $c$ is Equation 1, and PAOR is the slope angle in percent of the loose angle of repose,

$P A O R=\frac{\text { Exit face slope angle }}{\text { Loose angle of repose }} \times 100$

The proposed model is based on several simplifications which produce a conservative result when a uniform homogeneous isotropic soil with no defects or concentrated leaks is assumed. Such defects could lead to other mechanisms of internal erosion at much lower gradients. The first simplification is at a horizontal exit face assuming that the highest possible critical gradient matches Terzaghi's model in 
Equation 1. The second simplification is that the critical gradient is assumed to be 0 at the loose angle of repose. Both of these simplifications are conservative due to a possible hardened soil crust at the surface likely exhibiting higher resistance to heave by way of arching, higher unit weight, and a likely higher failure angle than the loose angle of repose. Both cases where the simplifications are made, laboratory tests showed higher critical gradients attributed to the soil arching and higher density than the loose soil state. Using these simplifications, the trend agrees precisely with Terzaghi's prediction when assuming a horizontal exit face, and the soil on the exit face can be assumed to have a minimal relative density. Figure 6 plots the normalized critical gradients with the proposed model.

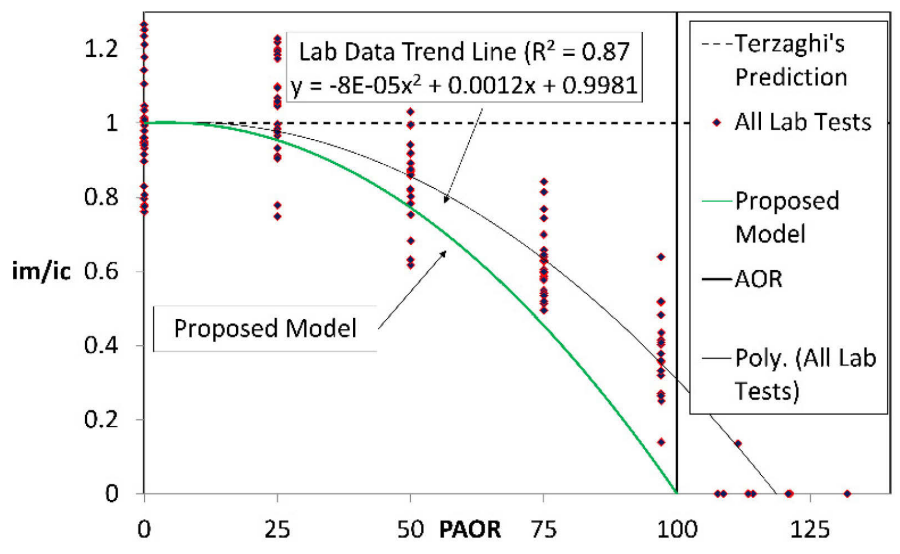

Figure 6. Proposed model plotted with laboratory trends.

As shown in Figure 6, none of the data points fall below the proposed model at 75 PAOR or greater. This depicts the conservativism of the proposed model resulting from using the loose angle of repose rather than the internal friction angle of the soil, especially at the steeper inclination angles.

\subsection{Comparison with other Methods}

Figure 7 plots a comparison between the proposed model, and the methods proposed by Terzaghi and O'Leary. The gradient shown is normalized to Terzaghi's method of which all three of these methods are based.

As previously explained, Terzaghi's method does not account for exit face inclination when calculating a critical gradient for heave, as shown by the constant line.

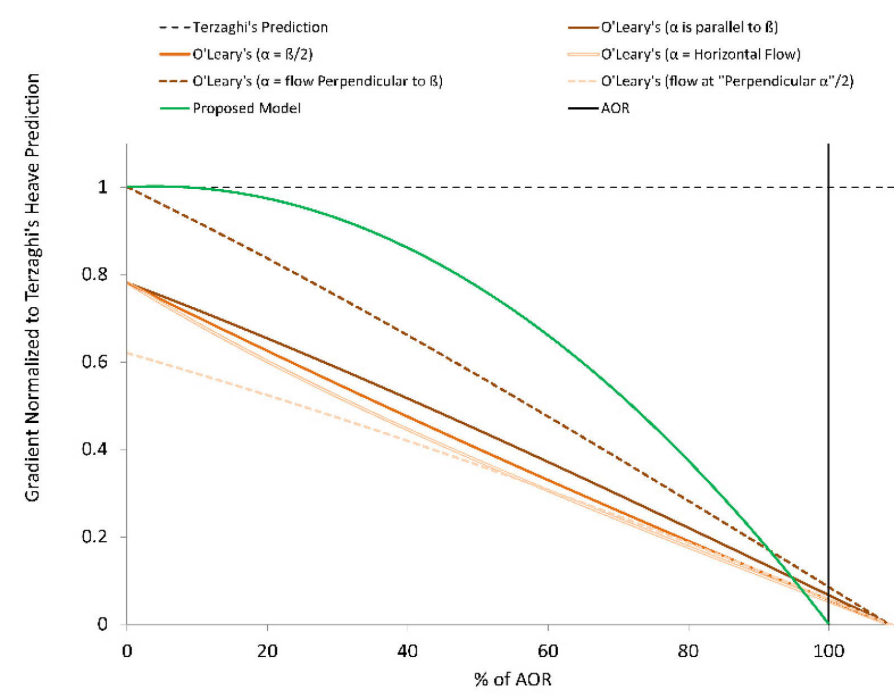

Figure 7. Comparison between proposed model and other methods.

O'Leary's method is plotted with five different scenarios corresponding to five different seepage angles. The plot assumes an internal friction angle of 38 degrees, a unit weight of $2 \gamma_{\mathrm{w}}$, and an AOR of 35 degrees. For situations where the flow angle $\alpha$ is parallel to $\beta$, half of $\beta$, and horizontal, the trend only marginally deviates from each other, with a maximum difference at approximately 50 PAOR. However, once the flow angle $\alpha$ becomes negative (flows upward), there is no similarity in the trends. This method also shows that for a horizontal exit face, heave will occur at smaller critical gradients when the flow angle is not vertical, which means a smaller force component in the vertical direction is required for particle detachment. This trend seems counterintuitive when considering a free-body diagram. The trend seen for perpendicular flow seems much more intuitive, starting at Terzaghi's prediction for a horizontal exit face and decreasing almost linearly to a zero gradient at the internal friction angle; however, the trend is not similar to the trends found in this research.

\section{INTERPRETING RESULTS OF CONSTRICTED EXIT TESTING}

\subsection{Comparison with Finite Element Analyses}

As is apparent from a comparison between Figures $2 \mathrm{~A}$ and 4 , the progression of erosion initiation through a constricted exit face is quite different than erosion initiation under uniform flow conditions, especially in the later stages of the erosion initiation. To investigate the mechanisms associated with the constricted opening, the observed behavior and pore pressure measurements were compared to a finite element model (FEM).

Figure 8 presents the base FEM with its boundary conditions. The test specimen is modeled with an 
axisymmetric FEM model centered on the centerline of the sample holder. The base of the model and the orifice at the top are modeled with constant head boundaries that can be adjusted to model the changing differential head. The remainder of the model is bounded by no-flow boundaries to represent the Plexiglas mold and the axis of symmetry. This model represents the test prior to any movement of soil particles.

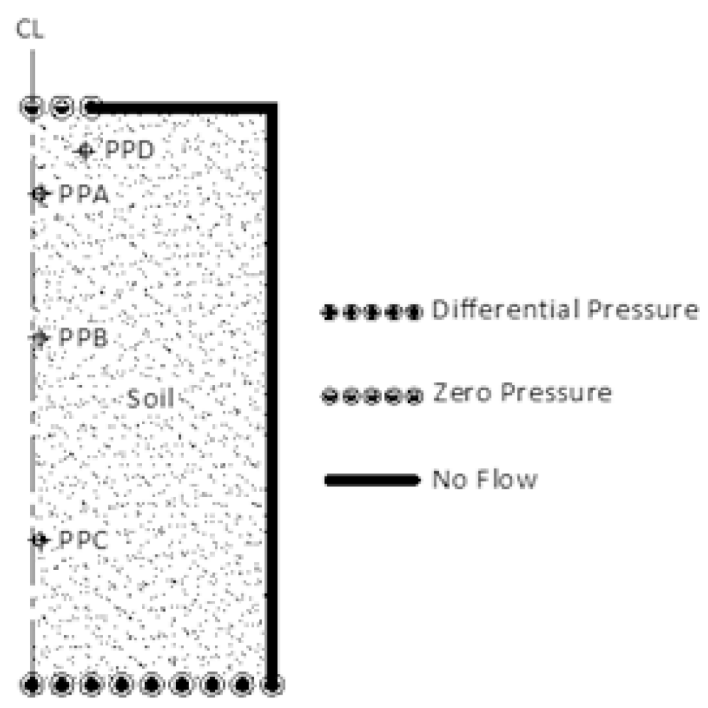

Figure 8. Base FEM model, prior to erosion initiation.

As erosion initiates in the sample due to increasing differential head, zones of soil at the top of the sample begin to loosen and in some cases become channeled with horizontal linear channels where soil particles have been removed (pipes). In the tests performed with unconstricted horizontal exit faces (ie Fleshman and Rice 2013, Swainston-Fleshman and Rice 2014a, 2014b), the density of the loosened soil was measured and the effect of the decrease in void ratio was assessed to be a 5-fold increase in hydraulic conductivity over the base soil. For purposes of this modeling we have denoted these loosened soils as Region 2 soils.

In addition to soil loosening, most constricted exit face tests exhibited a channeling behavior just below the top plate of the sampler. As the differential pressure increased in the test, the radius of these channels propagating out from the orifice increased. The channeled zone has been denoted Region 3 soils. Through judgment and trial-and-error analysis using the FEM model described below, the channeled zone was assessed to have a 50-fold increase in hydraulic conductivity over the base soil.

While some observations of the initiation of erosion could be observed through the top of the sample holder (mostly the propagation of Region 3 and heave into the orifice), most of the initiation of erosion occurs beneath the surface in the center of the sample as downward propagation of Region 2 . Thus, our only means for assessing the erosion progression was by estimating the extent of Regions 2 and 3 and observing how our estimates influence the flow regime using FEM analysis. A trial-and-error procedure was developed in which changes to the base FEM model presented in Figure 8 are made and the results are compared to the measured variations in the pressure sensor readings. The extent and shape of Regions 2 and 3 were modified until the results matched both the observed erosion and the sensor readings. A hypothetical arrangement of the regions at the top of the model are presented in Figure 9.

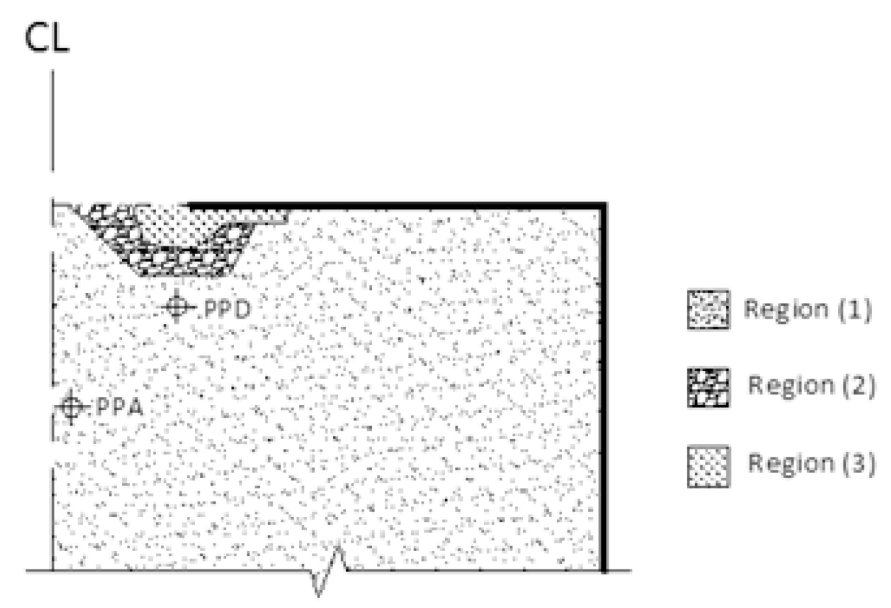

Figure 9. Upper portion of FEM model modified to model soil erosion.

Figures 10 and 11 present the results of the above described FEM analyses for tests run on graded Ottawa sand with orifice apertures of $2.5 \mathrm{~cm}$ and 0.64 $\mathrm{cm}$, respectively. The results in Figure 10 are presented for four different levels of differential head and while the results in Figure 11 are presented for three levels. Comparison of Figures 10 and 11 illustrates a variation in general behavior between large aperture and smaller aperture orifices. In the large orifices (Figure 10) the loosening of soil (Region 2) occurs around the edges of the orifice while the channeled region (Region 3) spreads a considerable distance toward the edge of the sample. In the smaller orifices (Figure 11) the loosened zone (Region 2) extends deeper into the sample while the channeled area (Region 3) is of much less extent. Similar behavior was observed in other soil types.

The differences in behavior between the tests with large and small orifices is likely due to the flow capacity of the orifices and how the gradients are dissipated in the surrounding soil. In the large orifices, the high flow volume results in a large bulb of high hydraulic gradients. However, since the soil erodes in the horizontal direction more easily than the vertical, the higher permeability Region 3 is able to develop before the Region 2 area reaches a great extent. The spreading Region 3 then dissipates the flow horizontally, thus, decreasing the vertical gradients and limiting the extent of Region 2. In the 
smaller aperture orifices there is less flow volume and thus Region 3 develops to a lesser extent. This allows the near vertical flow to remain concentrated resulting in a downward expansion of Region 2.

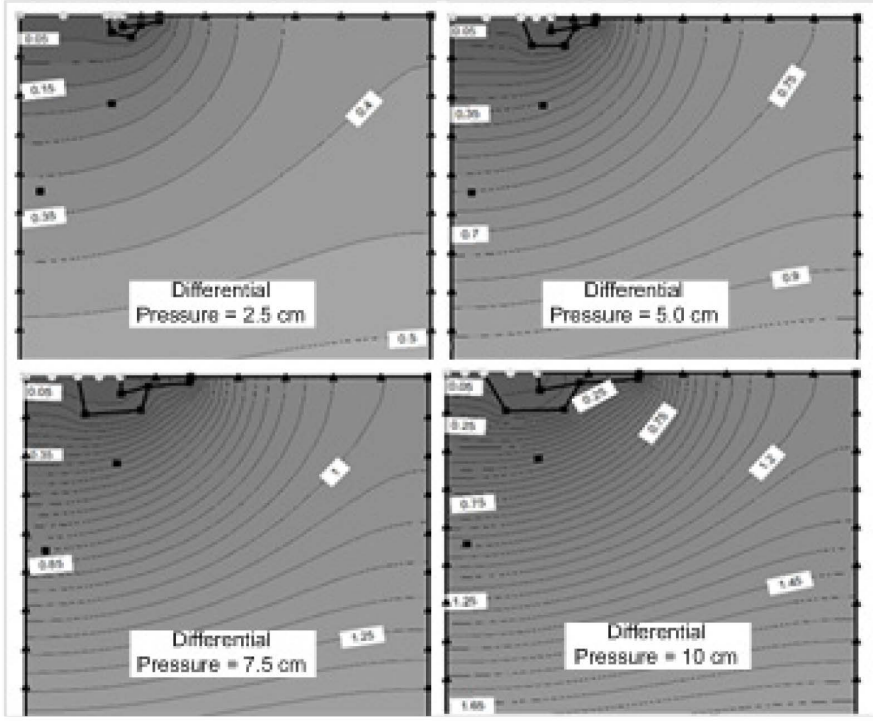

Figure 10. FEM model results showing progression of loosening soil in graded Ottawa with $2.5-\mathrm{cm}$ diameter riser.

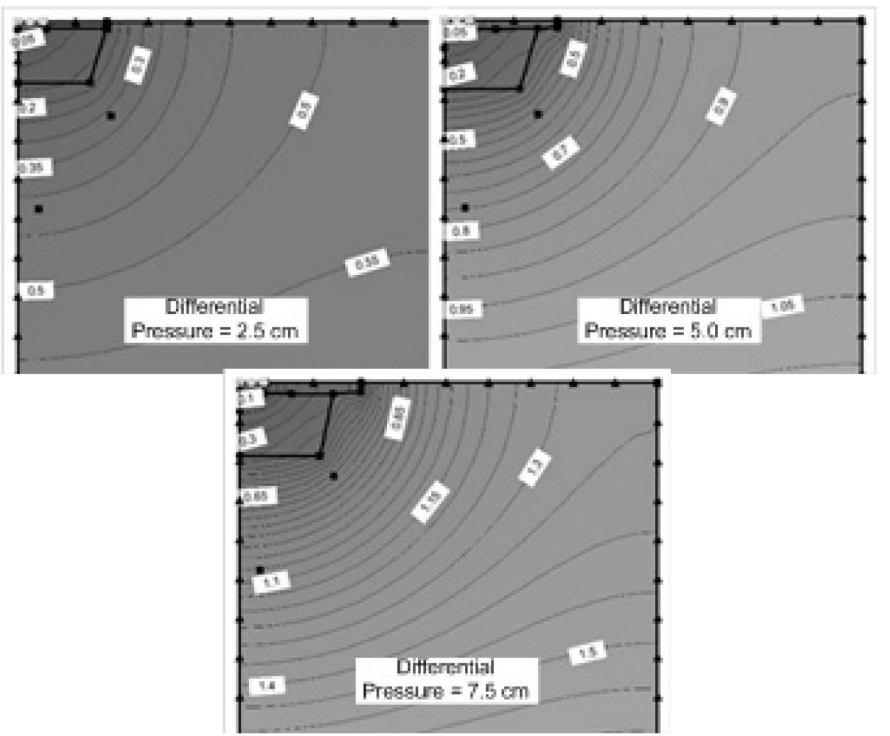

Figure 11. FEM model results showing progression of loosening soil in graded Ottawa with $0.64-\mathrm{cm}$ diameter riser.

The testing and analysis described above was performed on a variety of soil types representing a range of gradations, grain sizes and specific gravities. Further assessment of the results of these tests are expected to provide insight into the mechanics of the initiation and propagation of the BEP mechanism.

\section{CONCLUSIONS}

Laboratory testing programs were performed to assess the effects of exit face conditions on the initiation of internal erosion. Two conditions were as- sessed: an inclined exit face and a constricted exit face with converging seepage flow.

\subsection{Inclined Exit Face}

An empirical model is presented which can be used to estimate critical gradients for the heave mechanism of internal erosion where inclined exit face conditions exist with sandy soils. It is based on laboratory studies done at in the Earth Structures Laboratory at Utah State University. Current methods used in engineering practice today are summarized, and the results are compared to the proposed model. Engineering judgment should be used when calculating critical gradients for the heave mechanism, and if used, this proposed model should be compared to methods currently used in geotechnical engineering practice.

\subsection{Constricted Exit Face}

Tests were performed to assess the effects and behavior of converging flow on the initiation of internal erosion. The results were assessed using a back analysis technique that utilizes an axisymmetric finite element model to assess the propagation of zones of loosened soil and channelized soil as the differential head across the sample is increased. The results showed that the size of the aperture had a considerable effect on the erosion initiation behavior. These results also indicate that the initiation and propagation of the BEP mechanism is likely more complex than the two-phase models previously proposed by Schmertmann (2000) and Sellmeijer (Sellmeijer 1988). Assessment of these laboratory tests continues and additional results will be available in the near future.

\section{ACKNOWLEDGEMENTS}

This material is based upon work supported by the National Science Foundation (NSF) of the United States of America under Grant CMMI 1131518. Any opinions, findings, and conclusions or recommendations expressed in this material are those of the authors and not necessarily the views of NSF.

\section{REFERENCES}

Fleshman, Mandie 2012. Laboratory Modeling of Critical Hydraulic Conditions for the Initiation of Piping, Master's Thesis, Utah State University, Logan, Utah.

Fleshman, M. and Rice, J, 2013. Constant Gradient Piping Test Apparatus for Evaluation of Critical Hydraulic Conditions for the Initiation of Piping. ASTM Geotechnical Testing Journal, 36(6), 1-14. 
Keizer, Richard Allen Jr. 2014. Laboratory Study on the Effects of Exit Face Inclination of Critical Gradients, Master's Thesis, Utah State University, Logan, Utah

Keizer, R. and Rice, J. 2015. Evaluating the Mechanics of Piping Erosion Initiation through Laboratory Modeling. Proceedings of USSD Annual Conference, April 13-17, 2015. Louisville, KY.

Kovács, G., (1981), Seepage Hydraulics, Elsevier Scientific Amsterdam.

O'Leary, T., Vroman, N., Williams, C., Pabst, M. 2013. Critical Horizontal Seepage Gradients. ASDSO Journal of Dam Safety, 11(3), 33-39.

Schmertmann, J. H. 2000. The no-filter factor of safety against piping through sands. Geotechnical Special Publication No. 111, Judgment and innovation, F. Silva and E. Kavazanjian, eds., ASCE, Reston, Va., 65-133.

Sellmeijer, J. B. 1988. On the mechanism of piping under impervious structures. PhD thesis, Technical University, Delft, The Netherlands. TR diss. 1670.

Swainston-Fleshman, M., and Rice, J. 2014a. Evaluating the Mechanics of Piping Erosion Initiation through Laboratory Modeling. Proceedings of USSD Annual Conference, April 7-11, 2014. San Francisco, CA.

Swainston-Fleshman, M., and Rice, J. 2014b. Laboratory Modeling of the Mechanisms of Piping Erosion Initiation. ASCE Journal of Geotechnical and Geoenvironmental Engineering, 140-6.

Terzaghi, K. 1922, Der Grundbrunch an Stauwerken und Seine Verhutung [The Failure of Dams and Its Prevention], Die Wasserkraft, Vol. 17, 445-449.

Terzaghi, K., and Peck R. B. 1948. Theoretical Soil Mechanics in Engineering Practice. Wiley, New York.

USACE 1993. Seepage analysis and control for dams, EM 1110-2-1901, US Army Corps of Engineers, Washington DC, USA. 